\title{
Population ecology of spiny tailed lizard (Saara hardwickii) from lesser Cholistan desert, Bahawalpur, Punjab
}

Sangam Khalil*, Asrar Nisar, Tanveer Hussain and Ali Hassan

Department of Forestry Range and Wildlife Management, University college of Agriculture and Environmental Sciences, The Islamia University of Bahawalpur, 63100-Pakistan

*Corresponding author's email: sangamuaar@gmail.com

Citation

Sangam Khalil, Asrar Nisar, Tanveer Hussain and Ali Hassan. Population ecology of spiny tailed lizard (Saara hardwickii) from lesser Cholistan desert, Bahawalpur, Punjab. Pure and Applied Biology. Vol. 9, Issue 2, pp14361441. http://dx.doi.org/10.19045/bspab.2020.90149

Received: 26/12/2019 Revised: 22/02/2020

\section{Abstract}

Current study was conducted to collect data on population ecology of spiny tailed lizard (Saara hardwickii) in lesser Cholistan desert, district Bahawalpur. The density of lizard recorded was based on the observations of selected habitats and on presence of active burrows. Adults (23\%) were lower in the population followed by juveniles (35\%) and sub-adults (42\%) in number. Spiny tailed has territorial behavior and showed wide fluctuations with varying temperature. Lizards found to be agile in morning during hot season particularly during early hours of the day. During breeding season, lizards remain close to their burrows. They run quickly on the inappreciable disturbance from predators and back to their burrows while feeding. During study; it was observed that lizard eat its own shed skin to fulfill nutrient requirements. In various parts of the country including Cholistan, these lizards are frequently collected by illegal means and their fat and oil sold for medicine purpose. Poachers capture lizards and keep them in captivity by the brutal procedure of breaking the backbone. Detail study is required on ecology of spiny tailed lizard for its conservation in Cholistan desert; one of main area of its distribution in Pakistan.

Keywords: Cholistan; Density; Ecology; Saara Hardwicke; Spiny lizard

\section{Introduction}

Eastern spiny-tailed lizards belong to Genus Saara including three species as worldwide representation [1]. Saara hardwickii as representative of this genus has scattered distribution in Pakistan, India and Afghanistan [2]. It is the only lizard species in Pakistan which is herbivorous, found in dry areas of Cholistan desert and Sindh province largely in small fragmented populations. Sara hardwickii is heat-loving desert species [3].
Although these lizards are herbivores primarily, but when available they can eat insects occasionally [4]. It feeds on the vegetation, particularly on grasses [5].

Sara hardwickii breeds in May to June during summer season. Individuals can attain size of 13 to 24 inches at mature stage. Sara hardwickii incubation period is 15 to 20 days [6]. A female Sara hardwickii, depending on age and species can lay 5 to 30 eggs. Following copulation; eggs are laid in 30 days. The neonates are about $5 \mathrm{~cm}$ (2 in) in length from snout to vent, weighing 4-6 g 
and they rapidly gain weight following hatching during the first few weeks [4].

In Pakistan, these lizards are caught for their meat. Hindus with certain castes have habit to feed on its meat, especially during their marriage ceremony. It is white like chicken; said to be excellent; the tail is considered tasty but head and feet are not eaten. Body fat stored in the tail assumed to have medicinal value as it is boiled down and oil is used as a cure for impotence and embrocation. These lizards are frequently used in different parts of Pakistan and India for medicinal purpose [7].

Due to illegal trade and habitat destruction; this species is threatened. However, it has been considered as Data Deficient nationally due to lack of proper information [6]. This study provides data on spiny tailed lizard ecology based on information collected in Lesser Cholistan desert.

\section{Materials and methods \\ Study area}

Study was carried out in Yazman, district Bahawalpur as representative of lesser Cholistan desert, Punjab; respectively in Chak No. 54, 55, 56, 87 and 88. Yazman is a largest Tehsil of Bahawalpur District, in southern Punjab, Pakistan (Fig. 1). It is situated at a starting point of Cholistan, 32 kilometers from Bahawalpur and recognized as gateway to the Cholistan Desert. It is located at an altitude of $115 \mathrm{~m}$ (380 feet) with coordinate $29^{\circ} 7^{\prime} 30^{\prime \prime} \mathrm{N} 71^{\circ} 44^{\prime} 58^{\prime \prime} \mathrm{E}$. Average rainfall is between 7.5 to $12.5 \mathrm{~cm}$ and subsoil water is brackish.

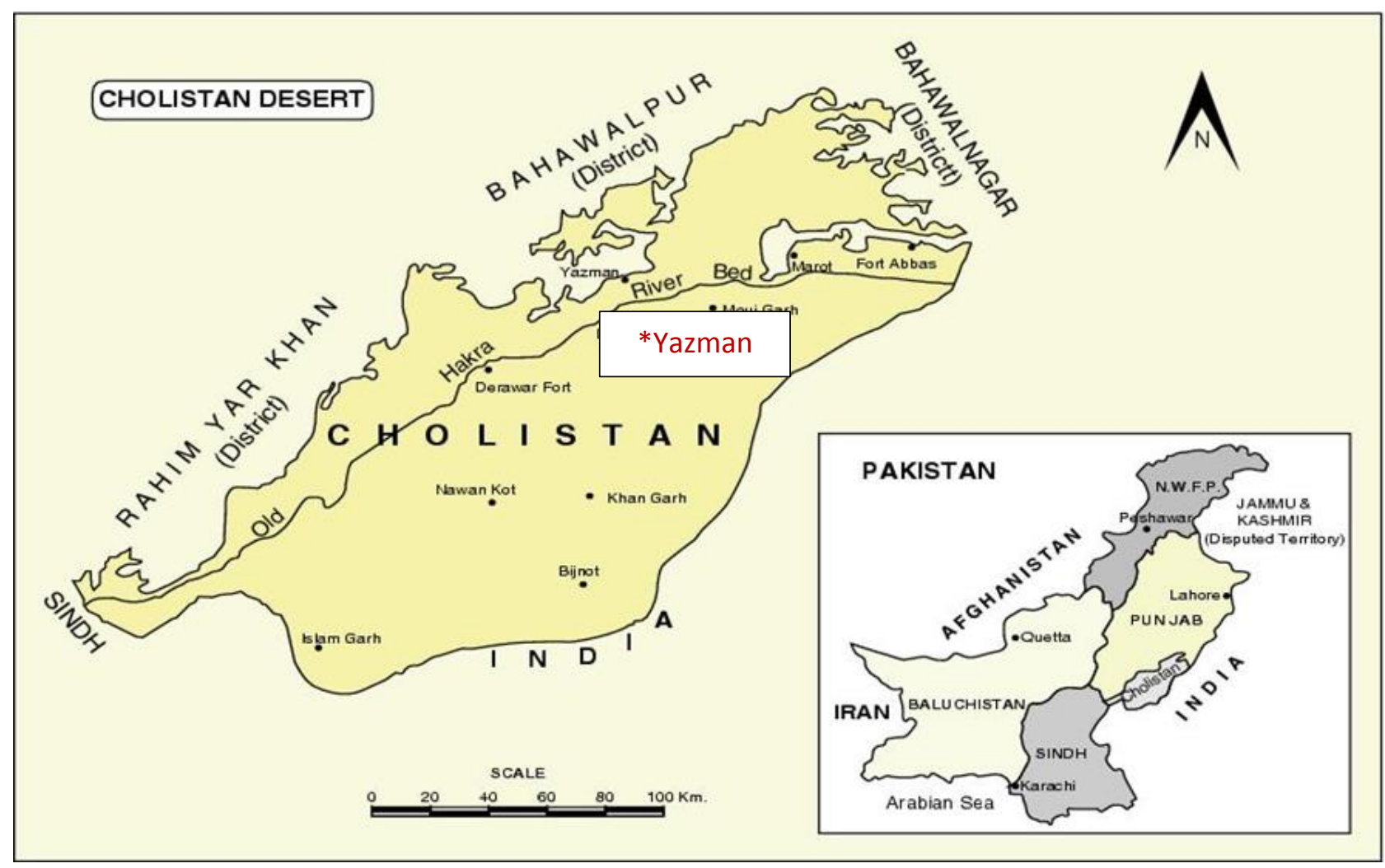

Figure 1. Map of study area (*Study area)

\section{Methodology}

Field surveys were undertaken during April 2017 to June 2018. During the study, 5 line transects of $500 \mathrm{~m}$ was established (one in each habitat) and 25 quadrates (5 in each habitat at distance of $100 \mathrm{~m}$ ) of 10x 10 size 
were taken randomly to collect the vegetation data. Each day was divided into two parts; the morning and the evening [7]. Sites in desert area were laid in Chak No. 54 DB, 55/DB, 56/DB, 87/DB and 88/DB. For each site, observations were repeated with a time gap of two minutes after every 20-minute interval. Observations were repeated on monthly basis to get the maximum data on habitat and lizard activity. Data was not recorded during rain when no lizards were sighted outside their burrows, and were shifted on the next few days for study. Observations were carried out with the help of Binocular from the boundary of the quadrats at a distance of 3m; Bushnell 7X35 $\mathrm{mm}$ and digital camera (Fuji film- fine pix, $\mathrm{S}$ 4200) with high resolution to note features such as habitat, activity and age of the lizards not causing their disturbance. Garmin eTerex 10 GPS navigator was used to take geo location of lizard burrowing.

\section{Results}

Estimate of lizards density in the current study was based on the presence of active burrows, animals seen in the field and on the no. of animals kept as pet in their habitat (recovered from poachers and sellers as information provided by wildlife staff) (Table 1, Fig. 2). Adults (23\%) were lower in the population followed by juveniles $(35 \%)$ then sub-adults $(42 \%)$ in number. This species found as a solitary burrow-dweller and is diurnal, but also found in colonies (Fig. 3). During study, at one site, three juveniles were emerged from one burrow, during feeding, which chased their mother, while other juveniles in the area foraged independently. It was found that the lizards affected by change in weather conditions and reflects extensive fluctuation in their activities.

Lizards were found to be agile in morning during hot season particularly during early hours of the day. They run quickly on the inappreciable disturbance from predators and back to their burrows while feeding. It was found that for feeding the lizards move from their burrow up to $20 \mathrm{~m}$ (Fig. 4). During feeding, they stand alarm. When run in an alert form, the tail is above ground while during its normal activities, tail is along the ground. When feed in colonies, they maintain considerable distance between them.

Throughout the study period, on normal days the lizards found active during whole day while during the rainy days they stayed in their burrow. The burrows of lizards have opening about circular in shape. They rest in their burrows after completing their morning feed, without making them seal, and after evening activity while they go into their burrow, seal them with loose soil.

Lizards make pairing for breeding, make their own burrows or sometimes occupied old burrows and feed together. During breeding season that was extended from mid of May to end of June in the study area, lizards remain close to their burrows and mating mostly done by male grasping female (Fig. 5).

In spiny tailed lizards, moulting was also observed, both in males and females during the summer season. One female and male was found by rubbing their body against the ground for shedding their dead skin. A dead skin was found near one burrow and it was also observed that they feed on shed skin.

Changes in body coloration were noted in these lizards, specifically, during day time. In addition, during morning the tail was light brown, but with passage of day time, body shifted to dark brown color.

Adult lizards in study area were observed feeding preferably plant species although wide variety of insects available, especially during the monsoon season. While juveniles and sub adults feed on both insects as well on plant parts, though juveniles mostly feed only on insects such as velvet mite, beetles, moths, caterpillars, grasshoppers and spiders.

The lizards were observed consuming five plant species during study, and habitat was 
dominated by Lani (Salsola baryosma). There was an overall relative abundance of Salsola baryosma (35) in their habitat, followed by Portulaca quadrifida (23), Boerhavia procumbens (17), Cyperus rotundus (11), Suaeda fruticosa (08) and Portulaca oleracea (06). The Indian Spiny- tailed Lizards' predators mostly found in study area are raptors and crows species. In one observation, a Sand Boa (Eryx johnii) was near lizard burrow and may use it as prey. During study, dead lizards were observed close to den of Bengal Fox (Vulpes bengalensis).

Table 1. Distribution of Spiny Tailed in study area, Lesser Cholistan

\begin{tabular}{|c|c|c|c|c|c|}
\hline Location & Coordinates & Season & $\begin{array}{c}\text { No. of Active } \\
\text { burrows }\end{array}$ & $\begin{array}{c}\text { No. of Animal } \\
\text { seen in field }\end{array}$ & $\begin{array}{c}\text { No. of Animal } \\
\text { kept as pet }\end{array}$ \\
\hline Chak No. 54 & $\begin{array}{c}29^{\circ} .163 \mathrm{~N} \\
71^{\circ} .772 \mathrm{E}\end{array}$ & Summer & 12 & 6 & 23 \\
\hline $\begin{array}{c}\text { Chak No. } \\
\mathbf{5 5}\end{array}$ & $\begin{array}{c}29^{\circ} .42 \mathrm{~N} \\
71^{\circ} .778 \mathrm{E}\end{array}$ & Summer & 34 & 20 & 0 \\
\hline Chak No. 56 & $\begin{array}{c}29^{\circ} .128 \mathrm{~N} \\
71^{\circ} .740 \mathrm{E}\end{array}$ & Summer & 21 & 18 & 14 \\
\hline Chak No. 87 & $\begin{array}{c}29^{\circ} .129 \mathrm{~N} \\
71^{\circ} .813 \mathrm{E}\end{array}$ & Summer & 28 & 16 & 10 \\
\hline Chak No. 88 & $\begin{array}{c}29^{\circ} .117 \mathrm{~N} \\
71^{\circ} .796 \mathrm{E}\end{array}$ & Summer & 24 & 20 & 16 \\
\hline & Total & $\mathbf{1 1 8}$ & $\mathbf{8 0}$ & $\mathbf{6 3}$ \\
\hline
\end{tabular}

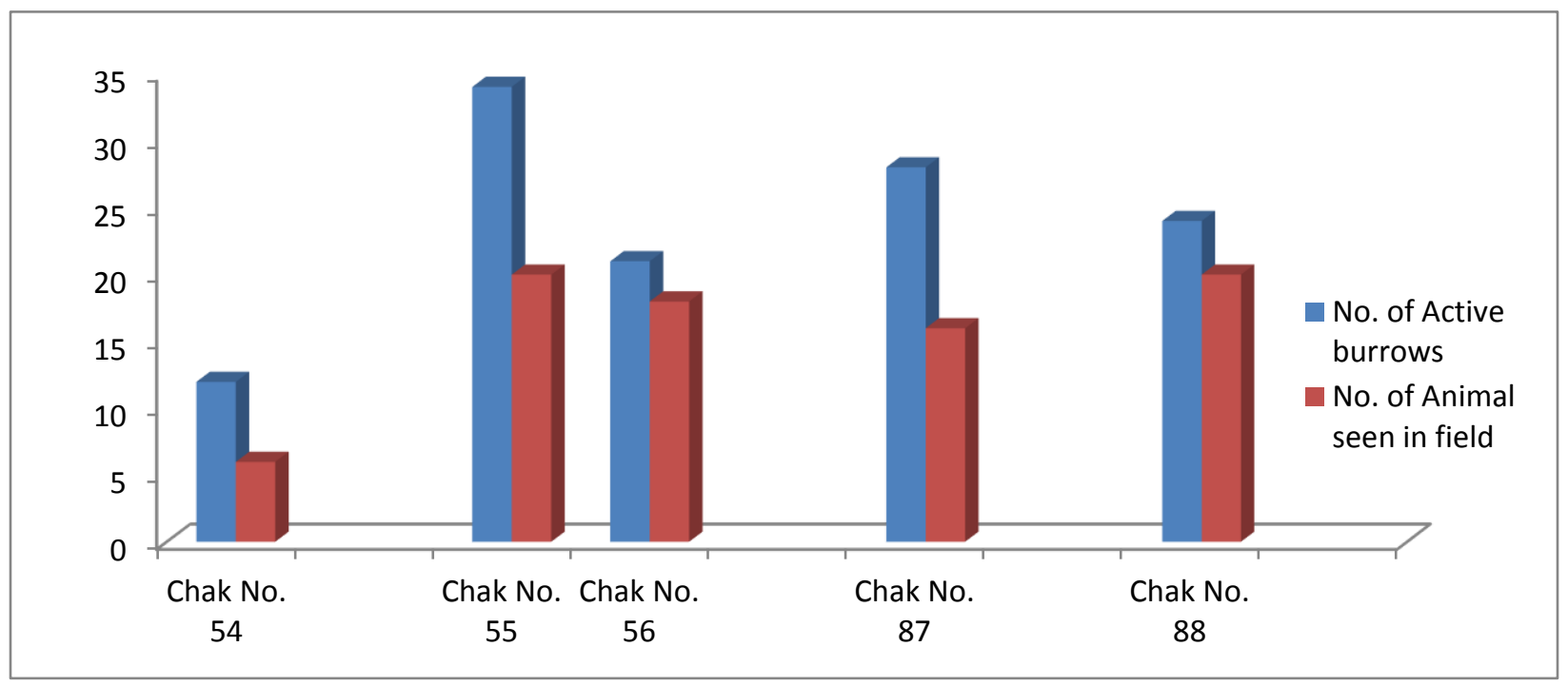

Figure 2. Graphical representation of Spiny tailed distribution in study area 


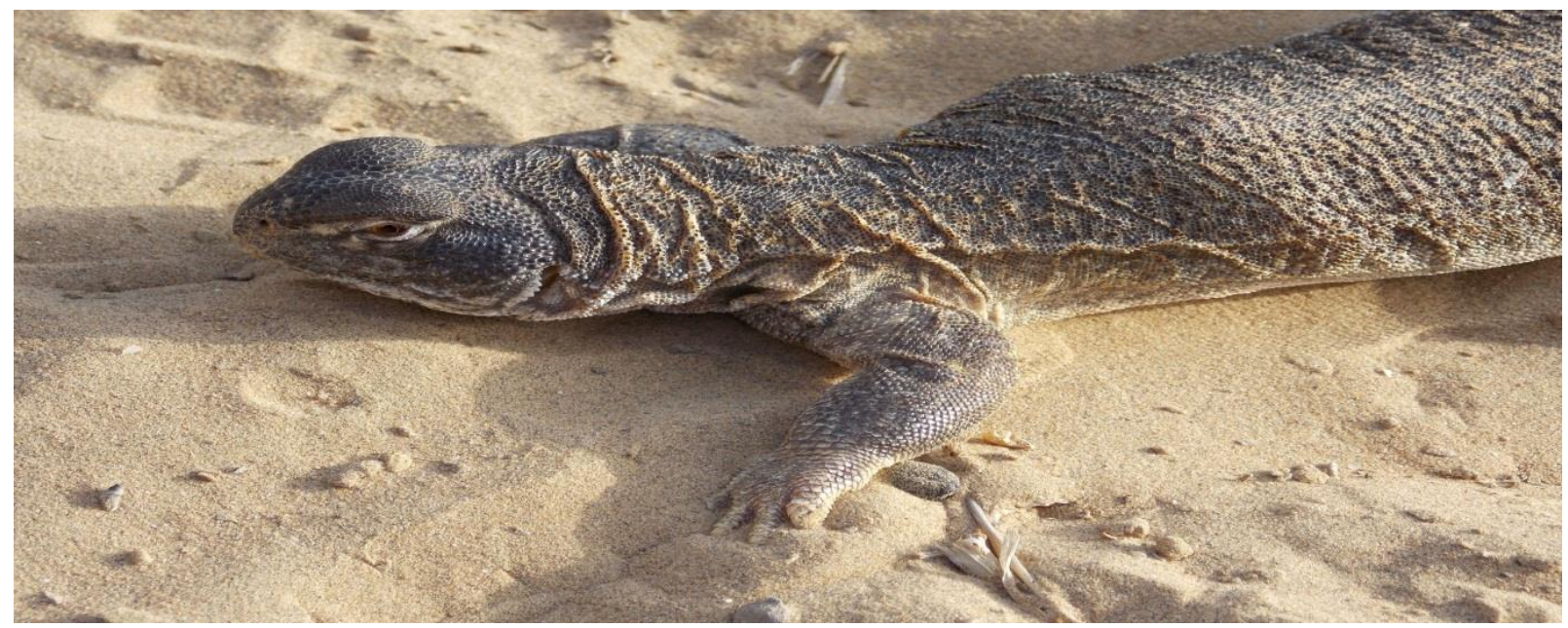

Figure 3. Indian Spiny-tailed Lizard Saraa hardwickii

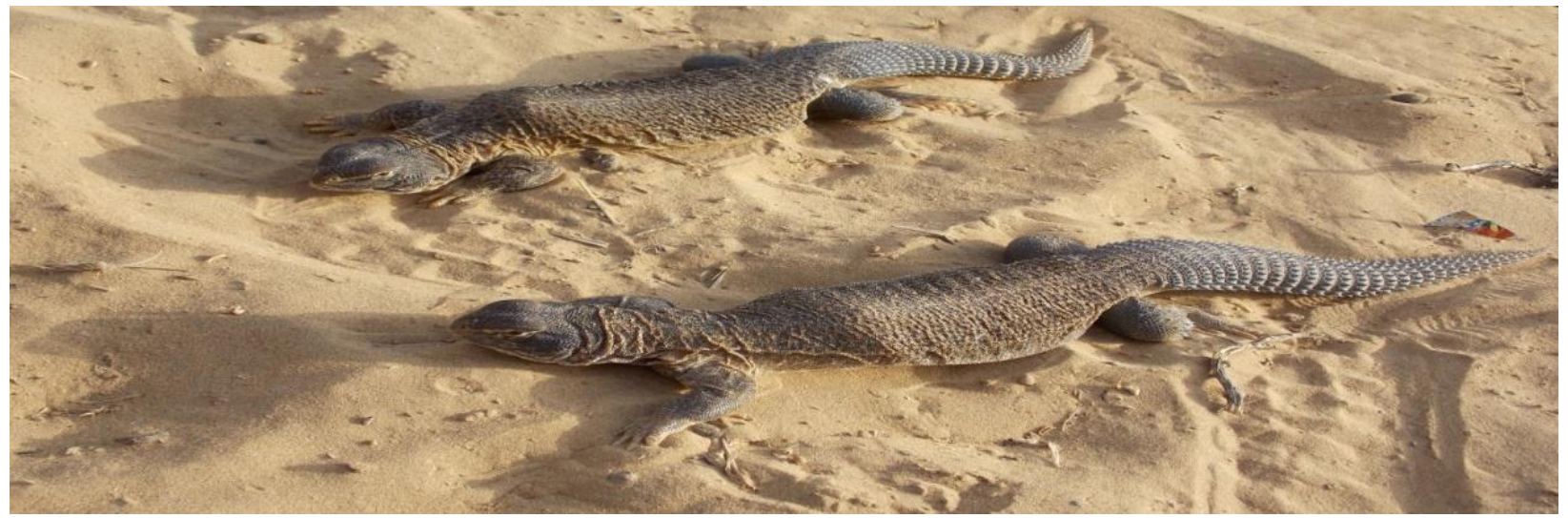

Figure 4. Two adult lizards chasing each other while feeding

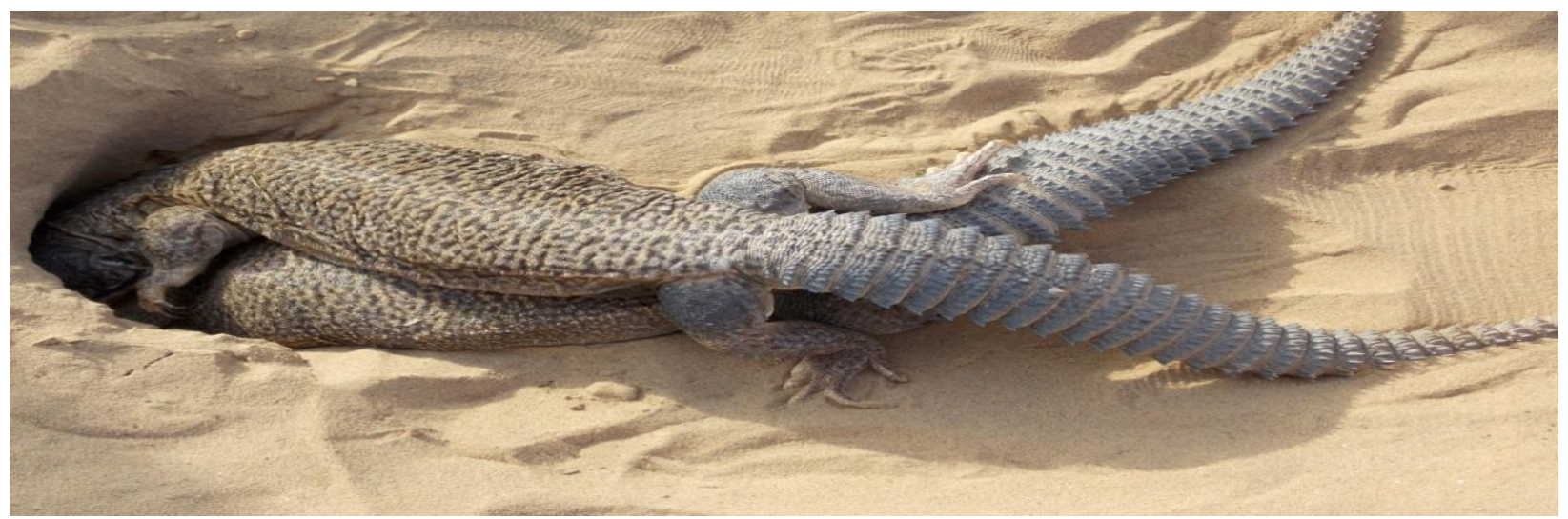

Figure 5. Two adult lizards during breeding

\section{Discussion}

Density of spiny tailed lizards's burrow was found slightly higher in comparison to the direct density in the study areas of Cholistan Desert. This certainly indicates that the study area is potential habitat for these lizards. It is also indicate during the study period, that some juveniles were sharing burrows with their mothers. The density of sub-adults was high in the population, succeeded by juveniles and adults 
respectively, during the study period as reported by [8]. According to [9]; the density of hatchlings was found higher than juveniles, sub adults and adults during the monsoon season in Run of Kutch area of India. The population of Indian Spiny-tailed Lizards was relatively high in an area dominated by Lani (Salsola baryosma); as it protects them from becoming deficient of water as well as provide them covers from predators; also described by [10]. During study period the lizard spent most of its time outside its burrow feeding which showed the lizard comes outside mostly for foraging, which is supported by [11]. In spiny tailed lizards, molting was also observed, both in males and females during the whole study. To fulfill nutrient requirements the lizard eating its own shed skin was observed during study; it was also earlier reported in other lizard which is described by [5] in his study.

\section{Conclusion}

Due to illegal trade and habitat destruction; this species is threatened. This study provides data on spiny tailed's population. Detail study is required on ecology of spiny tailed lizard for its conservation in Cholistan desert, one of main area of its distribution in Pakistan.

\section{Authors' contributions}

Conceived and designed the experiments: $\mathrm{S}$ Khalil, Performed the experiments: A Nisar \& A Hassan, Analyzed the data: T Hussain, A Nisar \& S Khalil, Contributed materials/ analysis/tools: A Nisar, A Hassan \& T Hussain, Wrote the paper: S Khalil.

\section{References}

1. Wilms TM, Wagner P, Shobrak M \& Bhome W (2009). Activity profiles, habitat selection and seasonality of body weight in a population of Arabian Spiny-tailed Lizards (Uromastyx aegyptia microlepis Blanford, 1875; Sauria: Agamidae) in Saudi Arabia. Bonner Zoologische Beiträge 56: 259-272.

2. Khan MZ \& Nazia M (2004). Study of Population Status and Natural History of Agamid Lizards of Karachi. Pak J Biol Sci 7: 1942-1945.
3. Bhanotar RK \& Bhatnagar RK (1977). Behaviour, colouration, lepidosis and preano-femoral pores in juveniles of Uromastyx hardwickii Gray. J Bomb Nat Hist Soci 74: 364-365.

4. Das SK \& Pandey VK (2005). Food, feeding, behavior and habitat preferences of Spiny-tailed Lizard (Uromastix hardwicki Gray, 1827) in the Thar Desert of Rajasthan, India. Tigerpaper 32: 30-32.

5. Pradhan S, Singh KM, Sangwan HS, Singh RN \& Singh RP (1973). Exploration of vertebrate predators for crop pests-1: food and feeding habits of spiny-tailed lizard, Uromastix sp. Ind J Ent 35: 148-149.

6. Molur S \& Walker S (1998). Report of the Workshop 'Conservation Assessment and Management Plan for Reptiles of India' (BCCP-Endangered Species Project). Conservation Breeding Specialist Group, Zoo Outreach Organisation, Coimbatore, India: 156.

7. Das SK, Dookia S, Das K \& Dutta SK (2013). Ecological observations on the Indian Spiny-tailed Lizard Saara hardwickii (Gray, 1827) (Reptilia: Squamata: Agamidae) in Tal Chhapar Wildlife Sanctuary, Rajasthan, India. J Threat Taxa 5: 3516-3526.

8. Ramesh M (2008). Final Report 'Status Survey of the Indian Spiny-tailed Lizard Uromastyx hardwickii in the Arid Regions of Rajasthan, North-Westewrn India'. Rufford Small Grants Foundation: 5.

9. Dutta S \& Jhala Y (2007). Ecological aspects of Indian spiny-tailed lizard Uromastyx hardwickii in Kutch. $J$ Bomb Nat Hist Soci 104: 255-265.

10. Cloudsley-Thompson JL (1992). Ecophysiology of Desert Arthropods and Reptiles. Springer-Verlag, New York: 203.

11. Cunningham PL (2001). Notes on the diet, survival rate, and burrow specifics of Uromastyx aegyptius microlepis from the United Arab Emirates. Asia Herpetol Res 9: 30-33. 